\title{
Peningkatan Kecerdasan Spiritual Warga Binaan Kristen Melalui Pendidikan Agama Kristen di Lembaga Pemasyarakatan Kelas IIA Salemba Jakarta Pusat
}

\author{
Desi Sianipar ${ }^{1},{\text { A Dan } \mathrm{Kia}^{2} \text {, Djoys Anneke Rantung }}^{3}$, Wellem Sairwona ${ }^{4}$ \\ Universitas Kristen Indonesia, Jakarta, Indonesia ${ }^{1,2,3,4}$ \\ desi.sianipar@uki.ac.id;_adan.kia@uki.ac.id; dyoys.anneke@uki.ac.id; \\ wellem.sairwona@uki.ac.id
}

\begin{abstract}
Abstrak
Peningkatan kecerdasan spiritual warga binaan Kristen lembaga pemasyarakatan (Lapas) Kelas IIA Salemba Jakarta Pusat adalah sangat penting karena pemahaman mereka akan nilai-nilai Kristen sangat kurang. Rendahnya kecerdasan spiritual telah melemahkan mental dan jiwa mereka sehingga mereka mudah jatuh ke dalam perbuatan jahat. Kecerdasan spiritual yang rendah telah menyebabkan mereka mengalami kesulitan dalam mengatasi masalah-masalah kehidupan baik ketika mereka menjalani hukuman maupun setelah mereka keluar dari Lapas. Kegiatan PkM ini bertujuan untuk mengatasi masalah para warga binaan Kristen, dengan meningkatkan kecerdasan spiritual mereka. Untuk itu, Tim PkM telah melakukan penyuluhan melalui Kursus Alkitab secara intensif setiap hari Rabu dan Kamis selama 6 bulan, khususnya menyangkut kepercayaan Kristen yang paling utama. Kegiatan ini telah diikuti oleh 60 (enam puluh) warga binaan Kristen. Hasil yang diperoleh dari kegiatan ini adalah sebanyak 23 (dua puluh) warga binaan dapat ditamatkan dan mereka menyatakan siap untuk terlibat aktif dalam berbagai pelayanan Kristen.
\end{abstract}

Kata kunci: Kecerdasan spiritual

\begin{abstract}
The increase of spiritual intelligence for the Christian prisoners at the Prison Class IIA Salemba Central Jakarta is very important because they lack understanding of Christian values. Low spiritual intelligence has weakened their mental and soul so that they fall into evil deeds easily. It also has caused them to experience difficulties in overcoming problems both when they are still in the prison and after they leave the prison. This program seeks to help to overcome their problems by increasing their spiritual intelligence. The community service team has taught the Christian fundamental beliefs to them and has trained them to have skills for doing Christian ministries. The spiritual intellegence has increased through intensive Bible Course held every Wednesday and Thursday for 6 months. There were 60 (sixty) partisipants, but at the end of Course, as the result, there were 23 (twenty three) graduates that are ready to involve in various Christian ministries.
\end{abstract}

Key word: spirituality intellegence 


\section{PENDAHULUAN}

Ada beberapa alasan mengapa penyuluhan ini dilakukan, yaitu: Pertama, pemahaman para warga binaan akan Alkitab Perjanjian Lama dan Perjanjian Baru masih sangat kurang, padahal sebagai seorang Kristen, pemahaman akan isi dan pesan Alkitab sangat mempengaruhi kecerdasan spiritual mereka. Kedua, kecerdasan spiritual para warga binaan sangat penting untuk memampukan jiwa mereka kuat dan handal dalam mengatasi permasalahan kehidupan mereka, khususnya ketika mereka kembali ke tengah masyarakat yang penuh dengan godaan dan tantangan. Ketiga, para warga binaan diharapkan dapat berperan positif di masyarakat, khususnya di lingkungan keluarga dan gereja, dengan memberi pelayanan yang mampu mereka kerjakan, misalnya menjadi teladan dalam keluarga, membantu pelayanan di kelas-kelas Sekolah Minggu, Remaja, Pemuda, orang dewasa, dan lanjut usia sesuai dengan keterampilan yang mereka peroleh dari program penyuluhan ini.

Masalah-masalah yang dihadapi oleh para warga binaan Kristen di Lapas antara lain:

Warga binaan pada umumnya belum memahami isi dan pesan Alkitab sehingga dasar yang mereka miliki kurang kuat dalam membentuk kecerdasan spiritual mereka.

Ada beberapa warga binaan Kristen yang setelah keluar dari Lapas, tergoda kembali untuk melakukan kejahatan dan kemudian tertangkap lagi dan masuk ke dalam Lapas. Para warga binaan Kristen kurang mendapat sambutan di dalam masyarakat luas setelah mereka keluar dari Lapas.

Adanya upaya penyadaran terhadap warga binaan sangat menolong mereka untuk mampu mengatasi masalah mereka sendiri dengan cara yang benar, yaitu dengan mengandalkan kecerdasan spiritual yang mereka miliki. Mereka mampu menyadari posisi dan peran mereka dalam gereja dan masyarakat, dan mereka termotivasi untuk aktif berkontribusi secara positif di dalam keluarga dan masyarakat.

Program ini telah dilaksanakan secara bertahap meliputi: survei kebutuhan warga binaan Kristen di Lapas Kelas IIA Salemba; perencanaan program pendidikan agama Kristen berupa Kursus Alkitab, penyusunan kurikulum, pengorganisasian program, penandatangan dokumen kerjasama atau Memorandum of Understanding (MoU) dengan pihak Lapas yang diwakili oleh Kalapas Salemba, pelaksanaan Kursus, dan evaluasi program. Di akhir Kursus Alkitab ini, kedua pihak yang bekerjasama telah memberikan Sertifikat Kelulusan kepada para warga binaan Kristen yang telah setia mengikuti Kursus dari awal sampai selesai.

Tujuan yang ingin dicapai dalam kegiatan ini adalah mereka mengalami peningkatan kecerdasan spiritual yang terlihat dari tumbuhnya rasa percaya diri yang 
memampukan mereka hidup lebih baik sesuai dengan aturan agama; mereka mampu berkarya di masyarakat setelah mereka keluar dari lembaga pemasyarakatan tersebut; dan mampu kembali kepada keluarga dan masyarakat luas dengan perilaku dan peran yang positif.

\section{METODE}

Kegiatan pengabdian kepada masyarakat dilakukan dengan memberikan penyuluhan/penyadaran melalui pembelajaran PAK berupa Kursus Alkitab kepada seluruh warga binaan Kristen. PkM dilakukan dengan menggunakan metode ceramah, diskusi, tanya jawab, dan praktik. Di akhir pembelajaran diberikan tugas-tugas dan tes. Semua metode tersebut digunakan untuk menanamkan pengetahuan utama dalam iman Kristen, melatih keterampilan mengajar secara sederhana, berkhotbah, dan memimpin ibadah kelompok kecil.

Kegiatan PkM ini dilaksanakan dalam bentuk Kursus Alkitab setiap hari Rabu dan Kamis selama 6 bulan oleh Tim yang terdiri dari 4 dosen tetap Program Studi Magister Pendidikan Agama Kristen dan dibantu oleh 8 mahasiswa, serta bekerjasama dengan 16 pengajar lain dari luar Prodi MPAK UKI. Setelah 40 sesi pembelajaran berakhir, ada 23 peserta yang dipandang layak untuk diluluskan dalam Kursus Alkitab ini.
Adapun kriteria kelulusan ditentukan dari: Mengikuti kursus dengan kehadiran minimal $75 \%$ dari 40 (empat puluh sesi/pertemuan/hari.

Mengumpulkan tugas-tugas tertulis mencakup pembacaan Alkitab, menelaah, dan menjawab pertanyaan-pertanyaan, dan diskusi, yang diberikan di sepanjang pelaksanaan kursus.

Lulus praktik berkhotbah dan memimpin persekutuan.

\section{HASIL DAN PEMBAHASAN}

Dilihat dari kehadiran, diskusi, tanya jawab, praktik, pengerjaan tugas-tugas, dan test yang diikuti, peserta tampak sangat antusias, sehingga dapat disimpulkan bahwa tujuan kegiatan ini telah tercapai. Ketercapaian target penyampaian materi pada kegiatan PkM ini sangat baik, karena materi penyuluhan telah disampaikan secara keseluruhan. Akan tetapi, penguasaan materi masih kurang dikarenakan latar belakang pendidikan, usia, dan tingkat kemampuan menyerap pelajaran berbeda-beda.

Berdasarkan uraian di atas, maka hasil PkM dapat dikemukakan secara ringkas, yaitu:

Para warga binaan yang berjumlah 60 orang mengalami peningkatan pemahaman tentang ajaran-ajaran pokok iman Kristen.

Dari jumlah 60 peserta kursus, ada 23 orang yang berhasil ditamatkan dan siap untuk membantu pelayanan-pelayanan 
Kristen. Sebagian besar warga binaan yang lulus dari kursus ini melayani di perkumpulan Kristen, baik di luar Lapas maupun di dalam Lapas.

Para warga binaan mengalami peningkatan kesadaran akan pentingnya kecerdasan spiritual. Hal ini terlihat dari perilaku positif untuk melakukan kebaikan di luar Lapas dan di dalam kampus.

\section{PEMBAHASAN}

PkM ini bertujuan untuk meningkatkan kecerdasan spiritual pada warga binaan. Yang dimaksud dengan kecerdasan spiritual (spiritual quotient or spiritual intellegence) adalah kecerdasan nurani yang menuntun manusia untuk berbuat baik dan mengembangkan dirinya secara utuh dengan menerapkan nilai-nilai positif. Kecerdasan spiritual membuat orang mudah mengatasi persoalan dan berdamai dengan pikiran dan perasaannya sehingga dia dapat mempertahankan kebahagiaannya. Dengan kecerdasan ini pula, orang akan mampu mengambil nilai dan makna dari pengalamannya. Seseorang yang memiliki kecerdasan spiritual ditunjukkan dengan adanya sikap yang adaptif atau kemampuan menyesuaikan diri dengan lingkungan; memiliki tingkat kesadaran yang tinggi terhadap dirinya dan lingkungan di sekitarnya; mampu bertahan dan mengatasi rasa sakit lahir-batin; serta mampu mengambil hikmah dari kegagalan ( $R$. Bambang Sutikno, 2014, 1-2). Dengan definisi ini dipahami bahwa kecerdasan spiritual menolong seseorang menjalani kehidupan yang penuh masalah dan tantangan ini dengan tetap kuat, stabil, dan mampu mengupayakan solusinya sehingga dia tidak mudah melakukan kesalahan atau kejahatan.

Pendidikan kecerdasan spiritual dalam pendidikan agama bertujuan untuk meningkatkan kecerdasan spiritual para warga binaan Lapas Kelas IIA Salemba. Menurut Sutikno, pendidikan SQ dalam pendidikan agama adalah bimbingan untuk mencapai kepribadian spiritual yang cerdas yang menekankan perbaikan sikap mental yang akan terwujud dalam perbuatan baik kepada diri sendiri dan orang lain. Pendidikan SQ merupakan pendidikan iman dan perbuatan baik yang dapat mendekatkan diri kepada Tuhan. Akan tetapi perlu disadari bahwa orang yang taat beragama belum tentu cerdas secara spiritual. Kecerdasan spiritual adalah kecerdasan yang bergantung pada bagian dalam diri manusia yang berhubungan dengan alam sadar. Hal ini membuat seseorang menjadi kreatif ketika menghadapi masalah dan dapat melihat makna yang terdapat di dalamnya, dan dapat menyelesaikannya dengan baik agar memperoleh ketenangan hati. (Sutikno, 2014, 5-6). 
Secara Kristiani, kecerdasan spiritual dipahami berkaitan dengan kepercayaan kepada Pribadi dan ajaran Yesus Kristus sebagai Tuhan dan Juru selamat. Alan E. Nelson mengemukakan bahwa kecerdasan rohani atau spiritual intelligence adalah proses yang menuntun kepada kedewasaan berdasarkan ajaran atau metode Yesus Kristus. Dalam hal ini, setiap orang tetap mempertahankan karakteristik mereka sebagai suatu pribadi yang unik, memiliki latar belakang, karunia, penampilan, dan rasa yang berbeda. Akan tetapi kecerdasan spiritual mereka harus terlihat melalui sejumlah karakteristik, yaitu: memiliki kasih, sukacita, kedamaian, kesabaran, kelembutan, iman, kebajikan, dan penguasaan diri, baik di saat tertekan maupun tidak (Gal. 4:22-23); mengikuti pengajaran rohani (Ibr. 6:1-2); memiliki iman yang kuat (Mat. 17:20); memiliki gaya hidup yang konsisten dengan iman (Yak. 2:14-26); mengakui kegagalan rohani (Mzm. 51); dan memiliki kerendahan hati dalam hal sikap dan pelayanan (Alan E. Nelson, 2010, 24). Kecerdasan spiritual tidak akan terlihat ketika seseorang hanya memiliki kepercayaan kepada Tuhan, tetapi tidak terbukti melalui praktik kehidupannya. Orang bisa saja terbuka kepada Yesus Kristus, tetapi tidak sepenuhnya menghormati ajaran Yesus. Selain itu, kecerdasan spiritual tidak bertumbuh ketika dia tidak memahami bahwa dia sepenuhnya bertanggungjawab untuk meningkatkan kedewasaan rohaninya.

Kecerdasan rohani perlu dikembangkan secara terencana melalui pendidikan agama Kristen. Hal ini juga ditekankan oleh Nelson. Dia menyatakan akan perlunya metode yang terencana, personal, dan efektif untuk mengembangkan kecerdasan spiritual. Metode yang dimaksudkannya adalah sejumlah prinsip yang akan menolong seseorang untuk bertumbuh secara spiritual melalui apa yang telah dilakukan oleh Yesus Kristus. Prinsip-prinsip tersebut adalah: 1) Para pengikut Yesus harus menjadi murid (learner, disciple) karena hal ini menyiratkan kerendahan hati dan pergumulan di dalam mengikut Tuhan supaya murid mengalami transformasi dan kedewasaan.; 2) Mengikut Yesus harus dalam perjalanan bersama-Nya karena Yesus adalah jalan (Mat. 4:19; Yoh. 14:6). Artinya, setiap murid-Nya mengikuti jalan yang ditunjukkan-Nya, dan itu akan menuntun pada kedewasaan dan pemenuhan spiritual. Semua hal bisa berubah di dalam dunia ini, tetapi murid-Nya tetap mengikuti jalan-Nya. Pengalaman perjalanan ini telah dilakukan Yesus bersama dengan murid-murid-Nya.; 3) Melakukan penilaian atas perjalanan spiritualitas sehingga dapat melihat perkembangan spiritualitas murid (Nelson, 2010, 28-34). Metode ini sangat sesuai dengan yang dilakukan Yesus Kristus, 
sehingga dapat dijadikan pedoman dalam meningkatkan kecerdasan spiritualitas warga binaan Lapas Kelas IIA Salemba Jakarta Pusat.

Berdasarkan teori di atas, maka Tim PkM telah menyelenggarakan pembelajaran Alkitab kepada warga binaan dengan menempatkan mereka bukan sebagai orang hukuman, tetapi sebagai murid-murid Yesus Kristus (the learners of Jesus Christ). Kepada mereka diberikan sejumlah pelajaran yang terencana, intensif, dan efektif, yaitu:

1. Pengenalan Ringkas PL (4 sesi)

2. Pengenalan Ringkas PB (4 sesi)

3. Karakter Kristen (2 sesi)

4. Spiritualitas Kristen (2 sesi)

5. Ibadah yang Hidup (2 sesi)

6. Mengajar Firman Tuhan secara Kreatif dan Kontekstual (2 sesi)

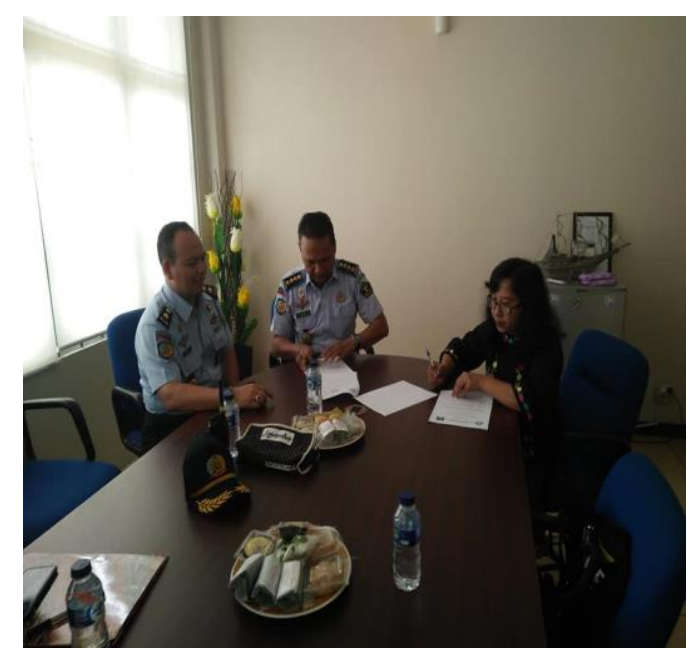

Implikasi dari temuan dalam PkM ini adalah kegiatan PkM ini sangat berdampak pada
7. Mengenal Bahasa Asli Alkitab: Bahasa Ibrani dan Yunani (4 sesi)

8. Allah Trinitas (3 sesi)

9. Manusia, Dosa, dan Keselamatan dalam Alkitab (3 sesi)

10. Gereja dan Tugasnya di Dunia yang Majemuk (3 sesi)

11. Metode Menjelaskan Alkitab (2 sesi)

12. Cara Berkhotbah (3 sesi)

13. Praktik Memimpin Ibadah dan Berkhotbah (6 sesi)

Semua pelajaran ini menjadi dasar bagi perjalanan spiritualitas mereka selanjutnya. Tim PkM juga membantu dalam melakukan penilaian atas perkembangan spiritualitas mereka. Selain itu, tentu Tim menekankan pada mereka bahwa mereka juga harus melakukan penilaian atas perjalanan mereka sendiri sehingga mereka dapat mengetahui peningkatan kecerdasan spiritualitas mereka.

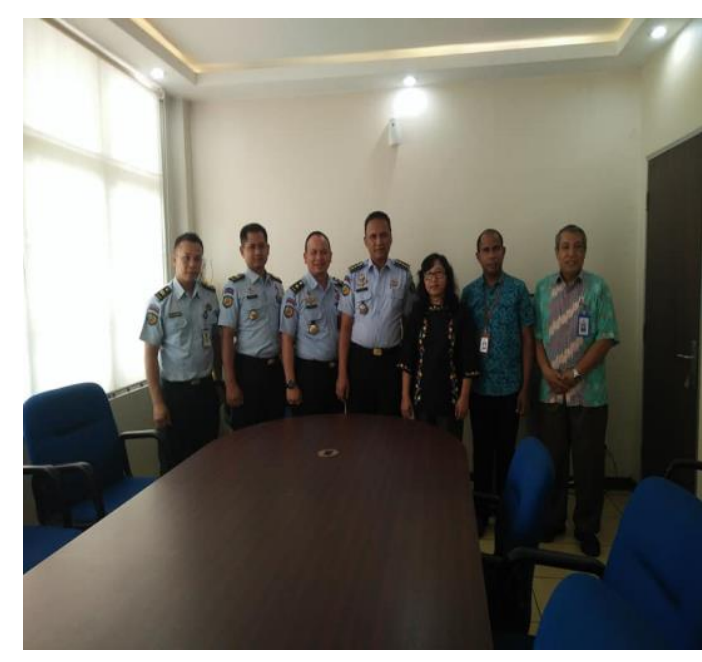

perubahan perilaku dan peningkatan pemahaman dan pengetahuan iman Kristen 
pada warga binaan. Karena itu, Kursus Alkitab ini sangat baik bila dijalankan di Lapas-lapas di Indonesia dalam rangka meningkatkan kecerdasan spiritual

para warga binaan.

Gambar 1.

Tim pada saat penandatanganan MoU dengan Kalapas

Kelas IIA Salemba Jakarta Pusat
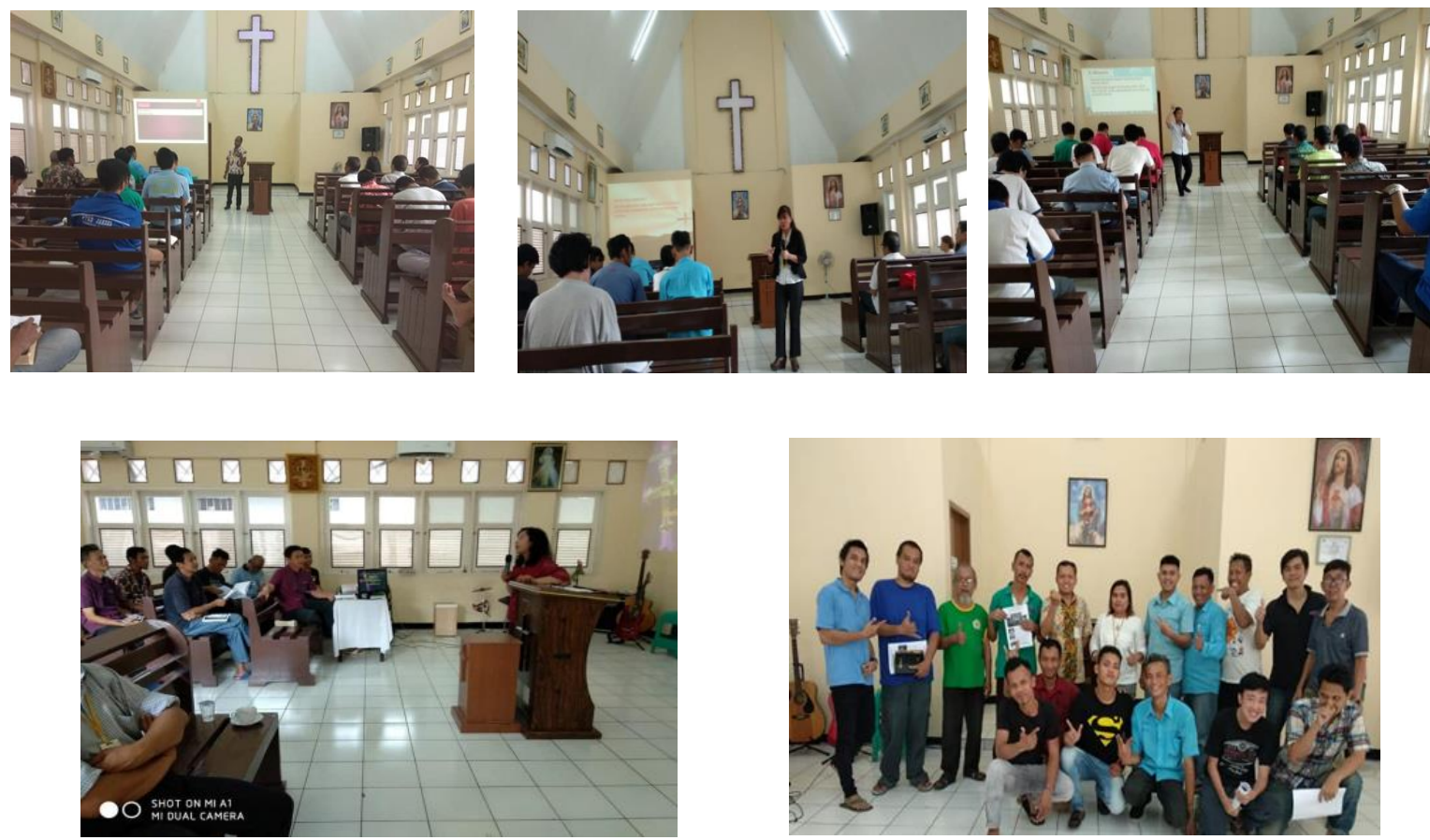

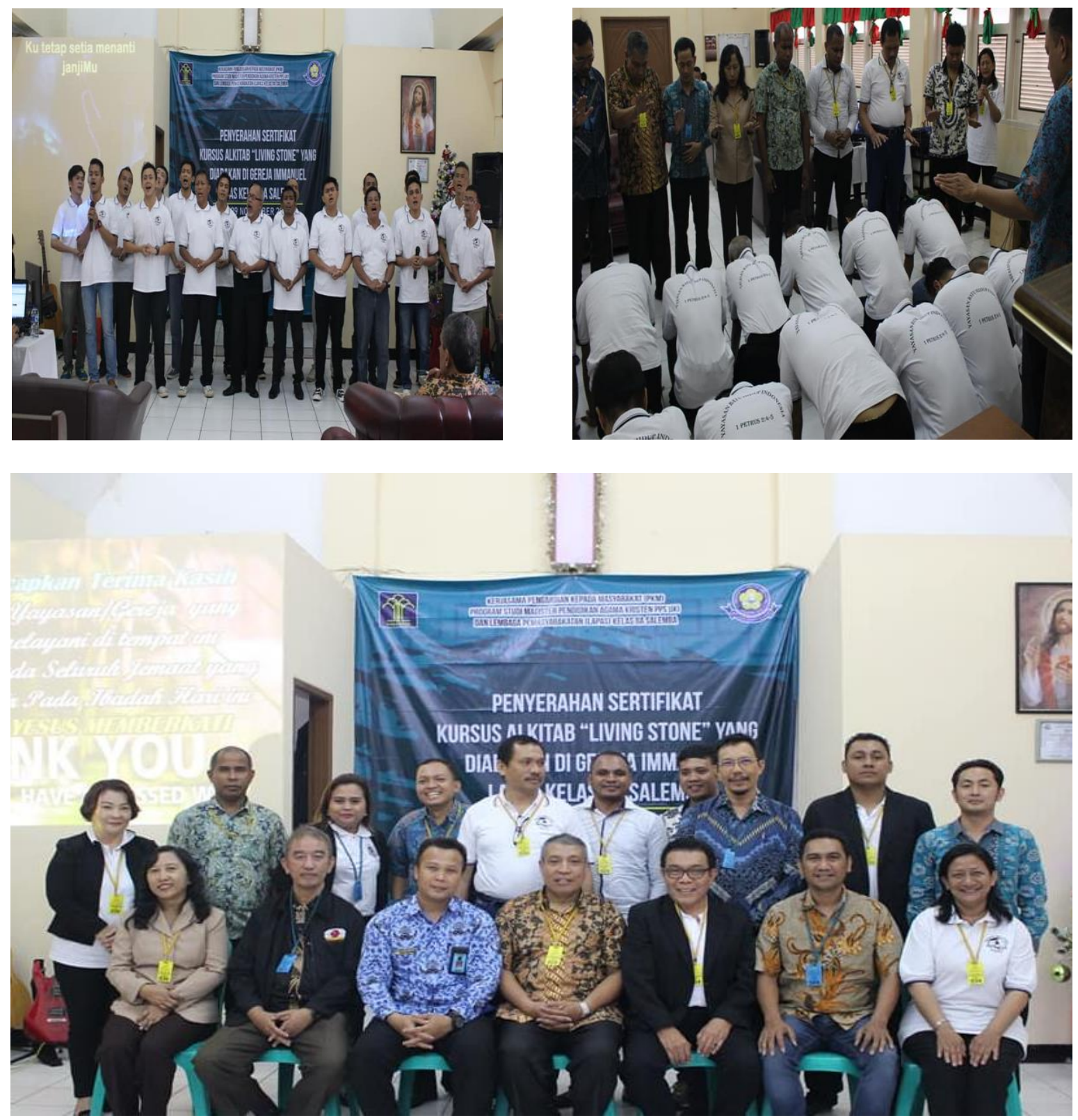

Gambar 2.

Dokumentasi pada saat penamatan para lulusan Kursus Alkitab

\section{SIMPULAN}

Program penyuluhan dapat diselenggarakan dengan baik dan berjalan dengan lancar sesuai dengan rencana kegiatan yang telah disusun meskipun masih ada beberapa kendala yang ditemukan dalam proses PkM ini. Kegiatan ini telah mendapat sambutan yang sangat baik dari pimpinan Lapas Salemba Kelas 2A, pembina kerohanian Kristen Lapas Salemba Kelas 2A, dan para warga binaan. Hal ini dibuktikan dengan permintaan dari 
pimpinan Lapas agar UKI tetap bersedia mengadakan Kursus Pengajaran Alkitab dan para warga binaan sangat bersemangat mengikuti Kursus tersebut, yang terlihat dari keaktifan peserta mengikuti penyuluhan dengan tidak meninggalkan tempat sebelum masa kursus berakhir. Berdasarkan evaluasi yang telah dilakukan dapat diajukan beberapa saran sebagai berikut: (1) Perlu dilakukan kegiatan Kursus lanjutan, (2) Perlu penambahan sarana penunjang kursus berupa Perpustakaan Lapas yang memungkinkan para warga binaan dapat menambah wawasan dan pengetahuan.

\section{UCAPAN TERIMA KASIH}

Dengan terselenggaranya kegiatan pengabdian kepada masyarakat dengan baik dan lancar, maka kami mengucapkan terima kasih yang sebesar-besarnya kepada:

Pimpinan Universitas Kristen Indonesia yang telah memfasilitasi dengan dana untuk pelaksanaan pengabdian kepada masyarakat sehingga dapat terlaksana dengan baik.

Pimpinan Lembaga Penelitian dan Pengabdian kepada Masyarakat UKI (LPPM) yang telah memproses mulai dari pengajuan proposal PkM hingga Tim dapat menyelesaikan PkM dan menyusun Laporan PkM, serta membantu publikasi hasil PkM dalam jurnal PkM LPPM UKI.
Direktur Program Pascasarjana yang telah menugaskan dosen-dosen Prodi Magister Pendidikan Agama Kristen dalam melaksanakan PkM ini.

Pimpinan Lembaga Pemasyarakatan (Lapas) Kelas IIA Salemba Jakarta Pusat yang telah bermitra dengan UKI sehingga mengijinkan Tim PkM melaksanakan kegiatan PkM pada warga binaan Kristen.

Pimpinan Yayasan Batu Hidup Indonesia yang telah bermitra dengan Tim PkM Prodi Magister Pendidikan Agama Kristen dengan memberi dukungan dana konsumsi setiap pertemuan dan tambahan tenaga pengajar.

\section{REFERENSI}

LPPM UKI (2018), Pedoman pelaksanaan pengabdian kepada masyarakat (PkM) Universitas Kristen Indonesia. Jakarta: Lembaga Penelitian dan Pengabdian kepada Masyarakat UKI.

Nelson, Alan E. (2010), Spiritual intelligence: Discover your SQ. Deepen Your Faith. Grand Rapids, Michigan: BakerBooks.

Sutikno, R. Bambang (2014), Sukses bahagia dan mulia dengan 5 mutiara kecerdasan spiritual: Kiat pencerahan dengan sentuhan modern dan nilai-nilai keagamaan. Jakarta: PT Gramedia Pustaka Utama. 